\title{
The bearing of biological fitness in humans and crops upon the emergence and spread of agriculture
}

\author{
Aaron Rottenberg \\ Department of Biotechnology, Ort Braude College, Karmiel, Israel; ar@braude.ac.il \\ Received 12 January 2013; revised 14 February 2013; accepted 28 February 2013 \\ Copyright (C) 2013 Aaron Rottenberg. This is an open access article distributed under the Creative Commons Attribution License, \\ which permits unrestricted use, distribution, and reproduction in any medium, provided the original work is properly cited.
}

\begin{abstract}
Past studies discussing the origins of agriculture have mainly emphasized changes in environmental and human-behavior factors as possible explanations for the shift from foraging to farming. This paper focuses on how increase in the biological fitness of both farmers and crops enabled the rapid evolution and success of farmers and agriculture. It is shown that the first plants under domestication achieved their superior fitness mainly as a consequence of some of their genetic and life-history traits. It led these species to be extensively integrated into human subsistence and eventually dominate the farmers' fields. Concurrently, the first farmers gained their enhanced fitness by producing food surplus and by acquiring extra social prestige and power, while materializing the tendency to higher reproduction rate, and eventually to the expansion of farming populations. The unbreakable dependence between high fitness crops and high fitness man, namely their coevolution is a key issue and a promising research area in the understanding of the human story and the origins of agriculture.
\end{abstract}

Keywords: Fitness; Prestige; Agriculture Origin; Founder Crops; Coevolution

\section{INTRODUCTION}

A major event in the human story is the transition of man from hunting and gathering to subsisting on cultivated plants and domesticated animals. Evidence indicates that this transition originated in the Near East some ten thousand years ago, mainly in a region known as the Fertile Crescent [1-4]. Scientists and scholars from different disciplines have tried to determine the various reasons that led to this transition. These reasons include environmental factors such as climatic changes, environmental stress and the lack of means of subsistence [5], as well as factors that relate to human behavior such as changes in the complexity of human society, the development of permanent settlements, concentration of populations in certain areas and even spiritual and ceremonial factors [5,6]. Several authors indicated an additional factor, namely the tight link that exists between the biological evolution of farming societies and the evolution of cultivated plants $[7,8]$. This link, brilliantly championed by Rindos [9] in fact underlies the phenomenal success of both humans and their crops.

One may wonder how it happened that man (for all his unique and remarkable capabilities) turned recently into a species with such a dazzling ability to subsist and reproduce; and at the same time, how it happened that plant species such as wheat or maize, whose incidence in the wild is relatively limited, "took over" vast expanses of land worldwide. It appears that in order to understand the initial transition of the hunter-gatherer societies to farming, and then, the rapid spreading and domination of farmers and agriculture throughout the world, one must examine the relationship between the following two elements: changes in the genetics and dispersal patterns of cultivated plants, and concurrent changes in human behavior. It will be discussed below how these two changes led directly to a higher biological fitness, to an increase in human populations and in the spreading of their crop fields, and in turn, to the rapid domination of the entire world by farmers and their crops. That is, the virtually symbiotic co-evolution of plants and man [9]. Two notes are necessary at this instant: firstly, the defining of biological fitness is beyond the scope of this paper and it will be regarded hereby simply as the ability to generate fertile offspring (see a comprehensive review in ref. [10]). Secondly, this paper focuses solely on the Near East as a case study for the origin and spread of agriculture but it may be found relevant to other worldwide regions as well. 


\section{CO-EVOLUTION OF CULTIVATED PLANTS AND MAN}

The dependence of human societies on cultivated crops (and domesticated animals) is absolute [5]. The large crops obtained by agricultural processes are what enabled the significant growth in human population, its existence and success. On the other hand, the existence and thriving of the cultivated crops too depend entirely on the growers, that is, on man. It is obviously clear, that today, an irrevocable dependency has been formed between man and his crops. The self-evident question is, therefore, whether this dependence is a "modern" affinity that is related to the enormous scope of human populations nowadays and their highly intensive agriculture or whether it has existed from the early days of agriculture? We shall see that such dependence is indeed extremely ancient and is related to the enhanced fitness of both crops and farmers.

\subsection{Evolution and the Fitness of Plants}

Each and every one of our cultivated plants has undergone changes in the course of the generations that have transpired since it was taken as a wild plant for domestication. Such changes were caused directly by man's subsistence behavior, whether consciously or not [3]. These evolutionary changes are clearly evident in the assemblage of plants known as the Founder Crops of the Near East (the first eight plant species that were taken to cultivation, namely einkorn wheat, emmer wheat, barley, pea, lentil, chickpea, bitter vetch and flax [1], soon followed by domestication of goats and sheep as well). This was the package that included the very founder crops which enabled the earliest known transition from foraging to agricultural society some ten thousand years ago. As Zohary showed [11], most of these eight founding crops were brought to cultivation in a single event or at most, very few events. Thus, it seems that from the moment a specific plant made that transition from the wild to being cultivated, an evolutionary process began that led to changes the consequences of which were that sometimes the plant could no longer grow independently.

Possibly the best known example of such a change in a crop is that of the non-shattering spike of wheat (whose seeds are not dispersed). This trait is rarely maintained in natural, wild wheat populations because the spontaneous genetic mutation that causes the indehiscence of the spike is a harmful mutation that results in the wheat grains failing to fall to the ground; thus they are not buried in it and do not survive [1,12]. Therefore, a plant with such a mutation will barely produce any progeny (that have this trait) and will disappear quietly with no trace [3]. In biological terms, the fitness of such a wheat plant is defined as practically close to zero. On the other hand, the exact same plant is of great value to the farmer, since the latter is interested in harvesting the grains before the spike disarticulates. The farmer, who, consciously or not, gathers into his granary non-shattering wheat spikes and sow the seeds the following season [13], will in any case increase the proportion of such non-shattering spikes in the field since each year he repeatedly selects from among all wheat mostly those that are indehiscent (here, as in the evolution of all cultivated plants, the main selecting factor is man with his subsistence behavior). Such a mutation, which leads to almost zero fitness in the wild species, in fact increases the fitness value of the plant as long as it is collected by man. Since man provides the plants in his fields better growing conditions than their relatives in the wild have, the fitness level of cultivated wheat in the field is higher than that of wild wheat in the wild. In other words, cultivated wheat produces and retains many more progeny (seeds) per area than does its wild relative. From here, the distance is very short to a complete takeover of the farmer's field by this nonshattering type.

Like in domesticated wheat, with its higher-fitness mutation, an "attractive" mutation is found also in the other founding crops of the Near East (for example as in the case of the loss of seed dormancy in peas, see ref. [1]). Such attractive mutations enhanced the fitness of each and every one of the eight founding crops through domestication, compared with their wild relatives.

Two additional traits that are common to all of the eight founding crops of the Near East are that they are predominantly self-pollinators and are all annuals [1]. In other words, the first farmers included in their assemblage of founding crops species of plants that manifested those mutations and life traits that benefit the farmer himself. That is, the self pollinating system of these plants directly implies the fixation of the above mentioned mutations and other genetic changes in the crop, creating true breeding crop varieties; and to the genetic isolation of the latter from its wild relatives $[1,13]$. In addition, these eight founder crops were all annuals that produce a new generation every year leading to a rapid evolution of the newly cultivated crops. This way of life implies not only quick evolution but also suitability to the intensive sowing-reaping system introduced by humans. Under this system, seeds are dispersed, grown, collected and then stored at the same year. Thus, seeds of annual crops will lose traits that do not fit this farming system. Once again, a good example is the loss of seed dormancy, that is, the inhibition of germination is in fact automatically selected against, leading to ameliorated crops. Under selection by humans, changes in annual plants may evolve rapidly and plant population structures might be changed considerably from one year to the next. Thus, during a human life span, several dozens of gen- 
erations of the annual plants are passed, turning this period to an intensive quick laboratory of crop evolution.

Thus, it seems that the first farmers have carefully chosen the particular species for their assemblage of founding crops. Indeed, those plants, chosen in the early days of agriculture, were plants that gave the farmer positive feedback for cultivation [5] and this, first and foremost due to their life-history traits, namely, annual habit, self-pollination mating system and the above mentioned beneficial mutations.

\subsection{Evolution and the Fitness of Humans}

We have already seen that the fitness of domesticated plants increased following the development of agriculture. Has man's fitness increased as well as a result? The answer is, of course, a resounding yes, and this can be seen in the meteoric increase in the number of human beings on earth. Indeed, the transition to subsisting on agricultural products enhanced man's fitness. Up until the shift to agricultural life, man subsisted on hunting and gathering - a method that proved itself well: in the long run, this way of life is relatively safe in terms of the availability of food, is nutritious and healthy in terms of food variety, and requires a relatively low investment of time [14-16]. On the other hand, agricultural life is much more demanding: crop fields are exposed to the fortunes of weather, to insects, pathogens and robbers. In addition, it was found that the health of those who adopted farming was deteriorated $[17,18]$, probably due to a poorer variety of food and the epidemics associated with agricultural life and the tremendous investment required in terms of labor [19]. The advantages of agricultural life are ostensibly negligible, aside from one advantage, which is indeed fundamental, and which tips the scalesthe advantage of higher fitness. In farming societies more children can be raised than in societies that subsist on hunting and gathering [20,21]. The advantage to the farming man (who overproduces food) is that more children, although constituting more hungry mouths, can also provide more working hands that will in turn help to enhance the farmer's economic situation. Wealth in itself constitutes an advantage that enables the farmer to attract women (see discussion hereafter), who, again, will produce more children with the farmer, and so on. The farming woman has the advantage whereby she is capable of raising and feeding a new child almost every year (rather than about every three to four years, as in many hunter-gatherer societies [15]). The social organization of farmers is such that it enables the "village" to care for the babies so that they are not totally dependent on their mothers to carry and nurse them. Farming mothers can, therefore, raise a greater number of babies concurrently, and on the whole can bring more children into the world, without risking their children's chances of survival [20,

\section{1].}

Summing up, the evolution of man and the evolution of his cultivated plants are interrelated by an unbreakable bond. This is, in fact, a process of co-evolution that, from a practical viewpoint, has been irreversible from the early days of agriculture. Plants that rapidly underwent changes during domestication could no longer exist as successfully without the conditions man provided them and without being dispersed in fields by man, whereas enlarging human populations that engaged in agriculture and produced more children could not subsist as successfully without the consistent surplus of food provided to them by such plants. The fitness-determining changes as described here are automatically selected for during the evolutionary process. That is, more progeny inheriting these evolved changes are produced, and those, in turn, will produce many new progeny who will bear and bequeath these qualities.

\section{HUMAN BEHAVIOR AND THE ADOPTION OF AGRICULTURE}

It was mentioned previously that the ability to have more offspring (higher biological fitness) is what tips the scales and leads to the almost absolute dominance of this way of life in human societies. However, one has to elucidate several factors that pertain to the behavior of different human societies in ancient times, their motives and the interaction between these societies. When discussing the transition from hunting and gathering to agriculture, one must remember that this transition was not a clearcut or a smooth one. Even in this day and age, huntergatherers can be found who sporadically engage in farming and vice versa [15,22]. Since both groups lived side by side, there was, and still is, contact between huntergatherer communities and agricultural communities in the form of marriage, commerce, labor and the exchange of knowledge [23,24]. Despite such relations, a great deal of antagonism probably existed (and still exists) between these two groups, as farmers regard hunter-gatherers as inferior whereas hunter-gatherers perceive the farmers' way of life disapprovingly, and in general, refuse to adopt it [15]. If so, why have societies of huntergatherers throughout human history yielded to farmers and their harsh way of life? Two main reasons can be given, both of which are tightly linked to biological fitness: numerical inequality and the aspiring of prestige.

\subsection{Numerical Inequality}

The numerical inferiority of the hunter-gatherers stems directly from the higher reproductive capability of the farmers. Following the increase in the high-fitness populations of farmers, the need arose to find new farming lands that would provide the requirements of the growing 
community. Since agriculture itself violates the balance of its surroundings and in the long run causes a lack of ecological stability, farmers are time and time again forced to find new and better lands for their multiplying offspring $[9,14]$. Thus, they spread to new territories and new frontiers. On these new frontiers they encounter neighbors, whom they must in fact expel. These neighbors are the hunter-gatherers. Then, the possible scenarios are that one of the two groups withdraws, or that the two groups intermix or that one adopts the other's way of life. Again, human history clearly describes the triumph of the agricultural societies. These societies, with their larger population and more complex social organization, at best caused the hunter-gatherers to recede to more remote regions, and at worst led to their disappearance, whether by conquest and killing, or by their assimilation to agricultural practice, ultimately turning them into farmers as well [5]. Occasionally, the conflict between these two ways of life did not necessarily culminate with a real clash and that the hunter gatherers adopted the agricultural way of life even before the farmers' frontier had reached them. In other words, some hunter-gatherers adopted the concept of agriculture by way of hearsay only; doing so, in fact, in order to gain prestige among their own people.

\subsection{Aspiring of Prestige}

Prestige is a most significant factor in the behavior of human beings [25]. It is most important in other animals as well, mainly with respect to the potential to attract mates and the ability to reproduce [26,27]. Indeed, the relationship between acquiring prestige (for instance, by excelling in food acquisition) and a male's higher reproduction ability is noted also among hunter-gatherers, but is much stronger in agricultural societies. In all agricultural societies (and, in this day, urban societies as well) the possibilities are greatest for those who aspire and are able to gain prestige. The structure of the agricultural society is such that it enables certain individuals to amass property, to engage in commerce, to attain a better economic status than other individuals and, as a result, to gain prestige. The immediate result is that such individuals who achieve prestige have a better chance both of attracting mates (materializing the tendency toward polygamy) and as a result, of having more offspring.

Commerce and the amassing of property are ancient component of human societies. These components in fact preceded agriculture by thousands of years [28], and thus they have a major role in the hunter-gatherer societies [29]. It can be assumed that hunter-gatherers, when seeing both the prestige achieved by a handful of farmers and its sociological and biological consequences, could not resist the temptation of improved economics and status that agricultural life could offer (similar to the conflict that exists even today in traditional hunter-gatherer societies). In other words, despite the many drawbacks of the agricultural way of life, it can ultimately lead to the amassing of property, wealth, prestige, and in turn to polygamy and to a greater number of offspring.

All the above mentioned behavioral traits, beyond being rooted in culture, are highly valuable with respect to fitness. As such, they are naturally selected for in the evolutionary process, since the many progeny (of those who have gained prestige, wealth or power) also inherit those behavioral traits that motivate accumulating wealth and prestige and will in turn pass these behavioral traits on to their offspring as well. Thus, the generation of abundant food [30] and gaining of prestige [25,26], offer those who possess either of them enhanced biological fitness; all the more so those who possess both.

\section{THE SPREADING OF AGRICULTURE}

We have seen that factors relating to: 1) the life history and genetic traits of the first agricultural plants; 2) the ability of such traits to be preserved and to evolve together with human societies; and 3) human behavioral elements relating to the amassing of property and prestige, can all lead to higher fitness of both farmers and their crops, and in turn to the potentially rapid spreading of the new lifestyle. Indeed, the human story tells us that this new lifestyle, which evolved in the Near East, namely, the use of the eight founding crops as a principal means of subsistence, spread quickly. For sake of comparison, the dispersion of modern human beings throughhout the world took at least several scores or hundreds of thousands of years, whereas the dispersion of farmers (or agriculture) took only a few thousand years [31,32]. Hence, from the original nucleus in the Fertile Crescent of the Near East, agriculture spread to Asia, Europe and the Mediterranean Basin at a mean rate of about one kilometer a year [31]. Genetic, linguistic and archaeological evidence from these areas show that in most cases the farmers themselves where those who migrated and brought with them the new lifestyle, while overriding local hunter-gatherer populations [30,33]. However, in some places, the rate of spreading was lower, the huntergatherers/farmers frontier remained unchanged for a longer period of time and the transition to agriculture was not straightforward [23,34].

As mentioned before, another scenario of much quicker spreading of agriculture involves the scattering of the idea of agriculture's benefits. Remote hunter-gatherers possibly adopted agricultural way of life even before the farmers' frontier reached them, following reports about wealth, prestige, polygamy and multitudes of children [33]. Such hunter-gatherers may have received the foun- 
der crops and agricultural-technological knowledge that they may have lacked, from the distant farmers themselves through commerce or marital ties. However, it is most important to note that even before agriculture time, hunter-gatherers possessed extensive botanical and environmental knowledge [16,35]. Hunter-gatherers have exercised vast varieties of mobility levels and different ways of subsistence, and different populations throughout the world manipulated their environment using irrigation, fire or weeding in order to obtain better yields of the wild plants in their environment [35]. Hence, the crucial point was not the acquiring of the concepts of botanical and agro-ecological knowledge of agriculture, but rather the ideas of agriculture's benefits.

If so, one may ask why almost all of the populations in the world turned agricultural within such a short time period [3], in fact, almost simultaneously? And if the botanical and agro-technical understanding have already existed, why was it suddenly manifested in the form of agriculture throughout the world? It seems that the answer again is-higher fitness for man. Perhaps, the trigger that apparently led to the implementation of the existing botanical knowledge and to a transition to an agricultural way of life in remote areas was the information arrived to these distant places regarding the benefits and advantage offered by this lifestyle. It is very likely to assume that even in remote areas, people heard about the novel farmers who were hard working but who owned property, gained prestige and fathered a multitude of children. So it seems, that several remote populations have tried this way of life as well, and the moment they did so, there was no turning back. From the time the main advantage of agricultural life was realized - that is, more offspring - the idea permeated rapidly and thus, populations throughout the world embraced the idea and became agricultural by using local plants and agro techniques (this merely suggests that people in these regions were fully aware of the potential of the local plants once they "decided" to practice agriculture). Those populations that did not-awaited their destiny, until the farmers arrived and took them over. This scenario also directly suggests that there is no need to explain the emergence of agriculture with several origins in several centers but rather with one origin only or two [36]. Even for the New World the assumption presented here is valid (i.e., an accidental voyager, merchant or a castaway arriving on the shores of the Americas several millennia ago and either practice farming by himself or relate an account about the new, harsh way of life that nonetheless carries with it great benefits).

From an evolutionary viewpoint, the moment the first pristine population of high-fitness farmers emerged, all other populations around had no choice but to become part of them or to act like them, when in any case, the ultimate result was to become high-fitness farmers as well.

\section{FUTURE PROSPECTS}

Perhaps the question of why humans have "invented" agriculture in the first place will remain elusive for some time, but it seems that as it enabled higher biological fitness for both humans and crops, this novelty quickly established itself, and its worldwide spread was inevitable. In future studies, major research directions should focus on the two major evolutionary changes involved in agriculture: 1) changes in human behaviors that are fitness-associated, mainly, subsistence and reproduction related; 2) changes in the crops' life-history, dispersal biology and genetics and most important, as Rindos [9, 37] emphasized, the unbreakable affinity between these co-evolutionary changes.

\section{ACKNOWLEDGEMENTS}

It is a great pleasure to thank Daniel Zohary and Allan Witztum for many enlightening discussions and for many years of friendship. I also thank the library services of Haifa University and Ort Braude College.

\section{REFERENCES}

[1] Zohary, D., Hopf, M. and Weiss, E. (2012) Domestication of plants in the Old World. Oxford University Press, Oxford.

[2] Lev-Yadun, S., Gopher, A. and Abbo, S. (2000) The cradle of agriculture. Science, 288, 1602-1603. doi:10.1126/science.288.5471.1602

[3] Diamond, J. (2002) Evolution, consequences and future of plant and animal domestication. Nature, 418, 700-707. doi:10.1038/nature01019

[4] Willcox, G., Fornite, S. and Herveux, L. (2008) Early holocene cultivation before domestication in northern Syria. Vegetation History and Archaeobotany, 17, 313-325. doi:10.1007/s00334-007-0121-y

[5] Murphy, D.J. (2007) People, plants and genes. Oxford University Press, Oxford. doi:10.1093/acprof:oso/9780199207145.001.0001

[6] Hayden, B. (1995) A new overview of domestication. In: Price, T.D. and Gebauer, A.B., Eds., Last Hunters-First Farmers: New Perspective on the Prehistoric Transition to Agriculture, School of American Research Press, New Mexico.

[7] Harris, D.R. (1989) An evolutionary continuum of peopleplant interaction. In: Harris, D.R. and Hillman, G.C., Eds., Foraging and Farming: The Evolution of Plant Exploitation, Unwin Hyman, London.

[8] Watson, P.J. (1995) Explaining the transitions to agriculture. In: Price, T.D. and Gebauer, A.B., Eds., Last Hunters-First Farmers: New Perspective on the Prehistoric Transition to Agriculture, School of American Research Press, New Mexico. 
[9] Rindos, D. (1987) Darwinian evolution and cultural change: The case of agriculture. In: Manzanilla, L., Ed., Studies in the Neolithic and Urban Revolutions, BAR International Series, Oxford.

[10] Krimbas, C.B. (2004) On fitness. Biology and Philosophy, 19, 185-203. doi:10.1023/B:BIPH.0000024402.80835.a7

[11] Zohary, D. (1999) Monophyletic vs. polyphyletic origin of the crops on which agriculture was founded in the Near East. Genetic Resources and Crop Evolution, 46, 133-142. doi:10.1023/A:1008692912820

[12] Salamini, F., Özkan, H., Bandolini, A., Schäfer-Pregl, R. and Martin, W. (2002) Genetics and geography of wild cereal domestication in the Near East. Nature Reviews Genetics, 3, 429-441.

[13] Zohary, D. (2004) Unconscious selection and the evolution of domesticated plants. Economic Botany, 58, 5-10. doi:10.1663/0013-0001(2004)058[0005:USATEO]2.0.CO ;2

[14] Brody, H. (2001) The other side of Eden: Hunters, farmers and the shaping of the world. North Point Press, New York.

[15] Lee, R.B. (1979) The !kung San. Cambridge University Press, Cambridge.

[16] Reed, C.A. (1977) Origins of agriculture: Discussion and some conclusions. In: Reed, C.A., Ed., Origins of Agriculture, Mouton Publishers, The Hague. doi:10.1515/9783110813487

[17] Cohen, M.N. and Armelagos, G.J. (1984) Paleopathology at the origins of agriculture: Editor's summation. In: Cohen, M.N. and Armelagos, G.J., Eds., Paleopathology at the Origins of Agriculture, Academic Press, Orlando.

[18] Eaton, S.B. and Eaton, S.B. (1999) Hunter-gatherers and human health. In: Lee, R.B. and Daly, R., Eds., Cambridge Encyclopedia of Hunters and Gatherers, Cambridge University Press, Cambridge.

[19] Larsen, C.S. (2006) The agricultural revolution as environmental catastrophe: Implications for health and lifestyle in the Holocene. Quaternary International, 150, 1220. doi:10.1016/j.quaint.2006.01.004

[20] Penington, R. (2001) Hunter-gatherer demography. In: Panter-Brick, C., Layton, R.H. and Rowley-Conwy, P., Eds., Hunter-Gatherers: An Interdisciplinary Perspective. Cambridge University Press, Cambridge.

[21] O’Connell, J., Hawkes, K. and Blurton Jones, N. (2002) Meat-eating, grandmothering and the evolution of early human diets. In: Unger, P.S. and Teaford, M.F., Eds., Human Diet, Bergin and Gravey, London.
[22] Hoffman, C.L. (1984) Punan foragers in the trading networks of Southeast Asia. In: Schrire, C., Ed., Past and Present in Hunter Gatherer Studies, Academic Press, Orlando.

[23] Zvelebil, M. (1986) Mesolithic societies and the transition to farming: Problems of time, scale and organisation. In: Zvelebil, M., Ed., Hunters in Transition, Cambridge University Press, Cambridge.

[24] Thorp, C.R. (2000) Hunter-gatherers and farmers: An enduring frontier in the Caledon Valley, South Africa. BAR International Series, Cambridge.

[25] Ridley, M. (1996) The origins of virtue: Human institutes and the evolution of cooperation. Viking, New York.

[26] Zahavi, A. and Zahavi, A. (1997) The handicap principle: A missing piece of Darwin's puzzle. Oxford University Press, Oxford.

[27] Betzig, L. (1997) People are animals. In: Betzig, L., Ed., Human Nature, Oxford University Press, Oxford.

[28] Ofek, H. (2001) Second nature: Economic origin of human evolution. Cambridge University Press, Cambridge. doi:10.1017/CBO9780511754937

[29] Bird-David, N. (1992) Beyond "the original affluent society”. Current Anthropology, 33, 25-47. doi:10.1086/204029

[30] Smith, E.A. (1997) Sex is not enough. In: Betzig, L., Ed., Human Nature, Oxford University Press, Oxford.

[31] Cavalli-Sforza, L.L. (2000) Genes, peoples and languages. University of California Press, Berkeley.

[32] Diamond, J. (1997) Guns germs and steel. W.W.Norton, New York.

[33] Bellwood, P. (2005) First farmers: The origins of agricultural societies. Blackwell Publishing, Oxford.

[34] Fuller, D.Q. (2007) Contrasting patterns in crop domestication and domestication rates: Recent archaeobotanical insights from the Old World. Annals of Botany, 100, 903924. doi:10.1093/aob/mcm048

[35] Keeley, L.H. (1999) Use of plant foods among huntergatherers: A cross-cultural survey. In: Anderson, P.C., Ed., Prehistory of agriculture, The Institute of Archaeology, Los Angeles, 6-14.

[36] Carter, G.F. (1977) A hypothesis suggesting a single origin of agriculture. In: Reed, C.A., Ed., Origins of Agriculture, Mouton Publishers, The Hague, 89-134. doi:10.1515/9783110813487.89

[37] Rindos, D. (1984) The Origins of agriculture: An evolutionary perspective. Academic Press, Orlando. 